Revista Monografias Ambientais - REMOA v. 14, 2015, p. 52-64

EDIÇÃO ESPECIAL: PÓS GRADUAÇÃO EM EDUCAÇÃO,

INTERDISCIPLINARIDADE E TRANSVERSALIDADE

- UNIPAMPA - SÃO GABRIEL - RS

\title{
Educação ambiental: uma abordagem através de gêneros textuais a partir de oficinas de leitura e produção de textos
}

Environmental Awareness Education: Textual Genres Approach through Reading and Writing Workshops

\section{Fátima Rosemilda Ferreira Duarte Borges ${ }^{1}$, Luciana Borba Benetti²}

\author{
${ }^{1}$ Pós-Graduanda do Curso de Especialização em Educação: Interdisciplinaridade e Transversalidade, Universidade Federal do \\ Pampa, São Gabriel, RS, Brasil. \\ ${ }^{2}$ Doutora em Engenharia Ambiental, Docente na Universidade Federal do Pampa/São Gabriel, RS, Brasil.
}

\begin{abstract}
Resumo
Entende-se por Educação Ambiental ações práticas que levem à construção de relações de responsabilidade com o meio no qual se vive como forma de perpetuação e de manutenção dos seres vivos no planeta. Diante deste contexto, o presente artigo versa sobre uma pesquisa-ação que relata práticas desenvolvidas na Escola Estadual de Ensino Fundamental Dr. Pery da Cunha Gonçalves localizada no município de São Gabriel/RS, no $8^{\circ}$ ano do Ensino Fundamental nas aulas de Língua Portuguesa. O principal objetivo do trabal ho foi desenvolver atividades que envolvessem o estudo da Educação Ambiental a partir da abordagem de gêneros textuais variados, proporcionando ações reflexivas e críticas da relação entre o homem e a natureza. A metodologia desenvolvida foi através de projeto com oficinas de leitura e produção de textos, abordando o gênero jornalístico de forma aprazível e cooperativa, aliada ao estudo do tema transversal. Um dos resultados importantes deste trabalho foi o fato de despertar o lado crítico dos alunos acerca de suas ações e avaliar as consequências de sua relação com a natureza, percebendo-se parte do meio no qual vivem.
\end{abstract}

Palavras- chave: Educação Ambiental, Interdisciplinaridade, Gêneros textuais.

\begin{abstract}
Environmental Awareness Education means practical actions to build relationships based on responsibility and reasonable use of nature resources and environment as well as the perpretation and maintenance of all the planet living things. Considering that the following article presents research data about projects developed at Escola de Ensino Fundamental Dr Pery da Cunha Gonçalves located in São Gab riel /RS , $8^{\circ}$ grade, subject of Portuguese Language. The main objective was study subjects and situations related to environmental awareness offering reflexive and critical actions to understand man and nature relation. Reading and Writing Workshops to produce texts using Journalistic Genre as well as the study of the transversal theme were used as methodology. One of the obtained results was waking up students to critical observations allowing them to evaluate how their life styles impact the environment.
\end{abstract}

Key words: Environmental Awareness Education, Interdisciplinary, Textual Genres. 
A Educação Ambiental é um dos temas transversais que mais se trabalha nas escolas, ainda que seja de forma isolada, nas aulas de Ciências ou nas datas comemorativas, como a semana do meio ambiente, por exemplo. Atualmente, a Educação Ambiental firmou-se como uma necessidade devido à degradação alarmante do planeta e ao crescimento de movimentos ecológicos que visam à conscientização da população em relação às suas ações. Sendo assim, as escolas começaram a desenvolver projetos interdisciplinares que pretendem dar maior ênfase aos temas transversais, dentre eles a Educação Ambiental, conforme o que prescreve os Parâmetros Curriculares Nacionais. Segundo os PCNs, a transversalidade é a forma de realizar uma prática educacional voltada para a construção da cidadania, problematizando as questões sociais que afetam diretamente os sujeitos, desenvolvendo uma postura mais crítica e ativa na sociedade no qual estão inseridos.

Segundo o que afirma esse documento, o ensino de Língua Portuguesa precisa ser repensado na medida em que o mesmo exerce grande influência no aprendizado de outras disciplinas, nas questões que envolvem leitura e escrita. Sabe-se da enorme deficiência de nossos alunos neste aspecto, pois muitos dos que terminam o Ensino Fundamental não adquiriram as competências necessárias de leitura, escrita e de compreensão dos textos.

O ensino de Língua Portuguesa tem papel essencial na formação da cidadania, pois possibilita a participação social através da comunicação na qual o homem tem acesso à informação, expressa- se defendendo suas opiniões, produzindo conhecimento e construindo o seu espaço na sociedade. Os PCNs afirmam:

\begin{abstract}
"Essa responsabilidade é tanto maior quanto menor for o grau de letramento das comunidades em que vivem os alunos. Considerando os diferentes níveis de conhecimento prévio, cabe à escola promover a sua ampliação de forma que, progressivamente, durante o Ensino Fundamental, cada aluno se torne capaz de interpretar diferentes textos que circulam socialmente, de assumir a palavra e, como cidadão, de produzir textos eficazes nas mais variadas situações." (1997, p.23)
\end{abstract}

Nessa perspectiva de ensino da língua com o papel social que ela possui, é adequada a abordagem do ensino de gêneros textuais e, em particular, do gênero jornalístico devido à influência que desempenha no letramento dos mais diversos indivíduos pela grande circulação na mídia. $\mathrm{O}$ enfoque do estudo, portanto, deve se basear na aprendizagem da manipulação do diversos textos, no seu uso e não somente no reconhecimento e classificação como é comum ao ensino nas aulas de Língua Portuguesa hoje em dia. Quanto ao estudo de gêneros jornalísticos, o autor Francisco Alves Filho ainda afirma:

“Um dos objetivos centrais do estudo de um gênero é justamente compreender os propósitos comunicativos recorrentes de um conjunto de textos que participa de um gênero. Isso pode ser extremamente importante para que o trabalho com qualquer gênero em sala de aula leve em conta funções reais para as quais os gêneros são de fato utilizados." (2011, p.36) 
A intencionalidade dos textos que circulam no meio social é um importante foco para debate em sala de aula, principalmente no que se refere às questões ambientais. O estudo dos gêneros propicia uma prática interdisciplinar na medida em que se pode abordar os temas transversais, através de atividades que proporcionem a leitura e a reflexão dos mesmos num processo de interação. Segundo Ivani Fazenda, o professor de línguas pode ser o mediador entre esta e o sujeito que aprende, com vista ao seu crescimento pessoal e social através do desenvolvimento de sua competência comunicativa. A autora ainda afirma que:

“... ao considerarmos a relação homem-mundo, verificamos que por ser a palavra condição de transcendência do homem, levando-o a sair de si e identificar-se com as coisas do mundo, conclui-se ser a leitura fator de ampliação dessa relação homem-mundo e, consequentemente, motor de transformação de próprio mundo." (2012, p.58)

Ao estabelecer a importância da linguagem na construção da história humana, o papel da leitura é construir um homem mais consciente, mais responsável por si e por todos que o rodeiam, levando-o a repensar suas ações em relação ao meio ambiente. Ainda, segundo essa autora, a interdisciplinaridade pode ocorrer entre duas disciplinas que se complementem, no caso, a Língua Portuguesa e a Educação Ambiental, numa ação recíproca, sem que percam suas especificidades, mas que haja uma interação numa perspectiva de troca de experiências, pois o pressuposto básico da interdisciplinaridade é a comunicação. Cabe ressaltar que o caráter interdisciplinar das atividades desenvolvidas está na cooperação dos grupos, nas relações dialógicas entre professora e alunos e nas atividades desenvolvidas pela leitura, interpretação, pesquisa e produções textuais.

\section{Caminhos percorridos}

O presente trabalho foi desenvolvido a partir do estudo de práticas pedagógicas nas aulas de Língua Portuguesa direcionadas aos alunos do $8^{\circ}$ ano do EF de uma escola estadual localizada na periferia do município de São Gabriel, no primeiro trimestre do ano de dois mil e quinze. O objeto de estudo refere-se sobre a dinâmica do uso de gêneros textuais em sala de aula, como forma de abrir espaço para reflexão das relações entre os sujeitos sociais e a natureza, bem como desenvolver atividades de leitura e escrita que visem à elaboração de conceitos e permitam a compreensão do mundo, nele interagindo de forma a impulsionar transformações que propiciem a melhor qualidade de vida.

Segundo Müller,

“A língua, como suporte de todas as ciências, possibilita ampla interação com EA através do acesso a textos que facultam uma visão abrangente e crítica da realidade. Eles oportunizam ao indivíduo a reflexão dessa realidade para que, por meio da produção de ideias daí decorrentes, atue sobre o seu grupo social, de modo a gerar mudanças qualitativas em sua vida." (p 64)

A metodologia desenvolvida foi baseada na pesquisa-ação, ou seja, o plano de trabalho foi realizado a partir do contexto em que o sujeito da ação está inserido. O Projeto Interdisciplinar foi 
organizado em duas partes compostas de oficinas de leitura, compreensão e produção de textos e atividades extracurriculares, como palestras e passeios. As oficinas de leitura e produção de textos foram direcionadas para o tema transversal Educação Ambiental, mais especificamente resíduos sólidos, pois este tema está em constante debate, já que a coleta seletiva está se tornando uma realidade no município há pouco tempo e as pessoas ainda não têm uma atitude consciente em relação aos resíduos produzidos em suas residências.

A pesquisa-ação é uma metodologia que transforma o indivíduo, pois parte da problematização da realidade, detectando o "problema" e buscando possíveis soluções, proporcionando reflexões, bem como, redirecionando as ações, pois esta metodologia permite uma flexibilidade para adequar-se às necessidades que os sujeitos possam apresentar durante o processo.

Baseando-se nessas considerações, as atividades desenvolvidas foram:

\section{Oficina 1: Exibição do filme "Ilha das Flores"}

Esta atividade tinha o objetivo de mobilizar os educandos para a temática da EA e sugerir reflexões sobre a relação homem-natureza. Após assistirem ao filme, foram formados grupos para debaterem alguns aspectos relevantes que o filme apresenta como:

_ Como o ser humano é apresentado na história?

_Quais os fatos históricos citados no filme?

_ Como é apresentada a relação de consumo no filme?

_Que parte lhe chamou mais a atenção? Por quê?

A turma em geral apresentou dificuldade em relacionar os fatos históricos citados com a temática do filme. Por isso, pediram para assistir mais uma vez e então fizeram um debate coletivo chegando a algumas conclusões sobre a relação homem e natureza e as consequências de suas ações para o meio ambiente.

Num segundo momento, foi organizado um círculo para debate e socialização de ideias. Visto que esta não é uma atividade muito praticada pelos alunos, verificou-se um pouco de dificuldade em organizar as manifestações orais. A oralidade ainda é uma atividade pouco destacada no meio escolar, por isso, foi necessário expor as regras de um debate, delimitar tempo para cada indivíduo e explicar que o debate é um espaço em que todos devem ter a oportunidade de participação. A atividade levou um tempo maior que o previsto, mas após os esclarecimentos necessários e a organização das tarefas, seu objetivo foi alcançado. 


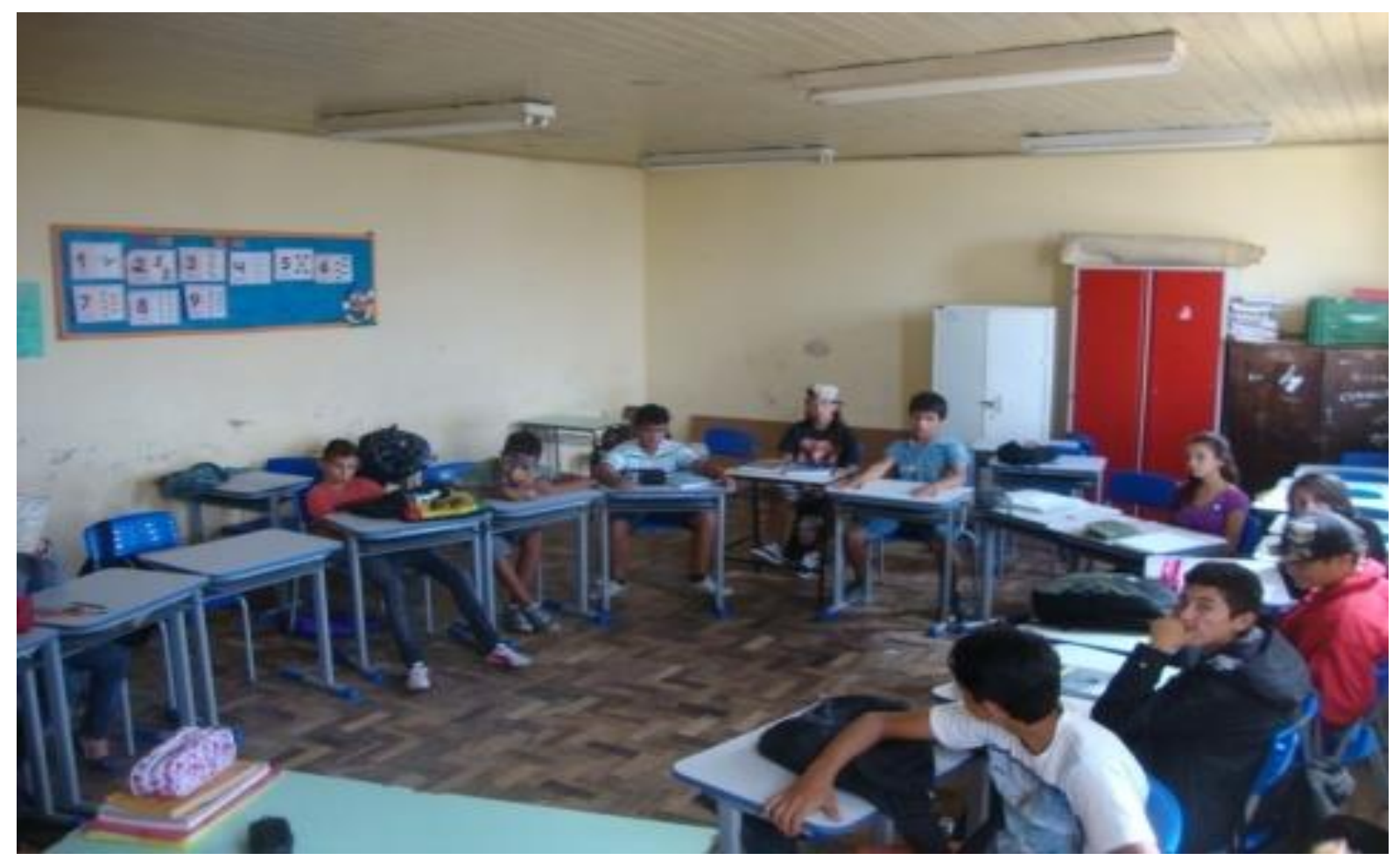

Figura 1: Debate sobre o filme realizado na Escola Estadual Dr. Pery da Cunha Gonçalves localizada no município de São Gabriel/RS, na turma de $8^{\circ}$ ano do Ensino Fundamental. Fonte: Autores

Oficina 2: Análise de gêneros jornalísticos afins ( tirinha, charge, notícia, carta de leitor)

Para a realização desta atividade foi necessário selecionar previamente vários exemplos de cada gênero. A temática dos textos selecionados foram variadas, incluindo o meio ambiente. Organizados em grupos, os alunos receberam, por sorteio, os textos. Cada grupo recebeu textos de um mesmo gênero. Após a leitura, desenvolveram-se as seguintes atividades:

_ Definição do evento deflagrador dos textos;

_Relato oral das estratégias que usaram para descobrir o evento deflagrador de cada texto.

O evento deflagrador é um fato que ocorreu recentemente e que pode gerar a escrita de vários textos dentro do meio jornalístico, como as tirinhas, as charges, a notícia e a carta de leitor. O conhecimento do evento deflagrador é muito importante para o leitor compreender o propósito comunicativo de determinado texto. O autor Francisco Alves Filho destaca a importância da relação entre o evento deflagrador e o gêneros para que seu estudo não seja tratado de forma superficial e descontextualizada, gerando grande desinteresse pela atividade escrita.

Nesse segundo debate, houve maior participação dos alunos e socialização de ideias com mais interesse pelas tirinhas e pelas charges. Observou-se grande dificuldade do grupo que ficou com o gênero charge em compreender a temática dos textos, talvez pelo pouco contato com este tipo de texto.

\section{Oficina 3: Produção escrita coletiva}

Os mesmos grupos organizados na oficina anterior elaboraram um evento deflagrador. Depois, por meio de sorteio, cada grupo recebeu a proposta de criar um texto a partir da temática recebida. Assim produziram textos com diferentes temáticas em diferentes gêneros. Os textos foram expostos em mural na escola. 
Foi uma atividade prazerosa, na qual os alunos participaram ativamente de atividades de leitura, compreensão e produção de textos com muito interesse e de forma reflexiva. Como a atividade foi feita em grupos, coube a cada grupo a correção e revisão dos textos produzidos com a ação mediadora da professora. As atividades acima citadas foram adaptadas de sugestões dadas pela obra do autor Francisco Alves Filho, 2011.

\section{Oficina 4: Análise de notícia}

Os alunos, reunidos em pequenos grupos, receberam um jornal local com uma notícia sobre coleta seletiva. Após a leitura foram propostos alguns temas para discussão:

_ Evento deflagrador da notícia;

_ Propósitos comunicativos explícitos e implícitos da notícia lida;

_ Localização de informações de dão credibilidade à notícia;

_ Grau de isenção;

_ Valor das citações e suas funções.

A análise destes dados exigiria um certo grau de maturidade e conhecimento do gênero para a compreensão das mensagens implícitas que são abordadas no texto através de uma leitura crítica. Portanto, foi necessário o direcionamento das questões com a mediação da professora, sempre auxiliando no sentido de que os próprios alunos localizassem todas as informações expostas na notícia. Além disso, destacou-se que a notícia é um tipo de relato (usando a classificação de SCHNEWLY E DOLZ, 2004) que tem por característica principal dar a ideia de objetividade, de isenção ao fato relatado, porém nem sempre isso acontece, principalmente em jornais locais que apresentam um lado tendencioso e muitas vezes, político. A atividade foi muito proveitosa porque despertou o lado crítico do aluno e sua curiosidade de forma que observou- se a completa atenção voltada para a leitura naquele momento. Algo que, na maioria das vezes, é bem difícil de se manter numa atividade como esta.

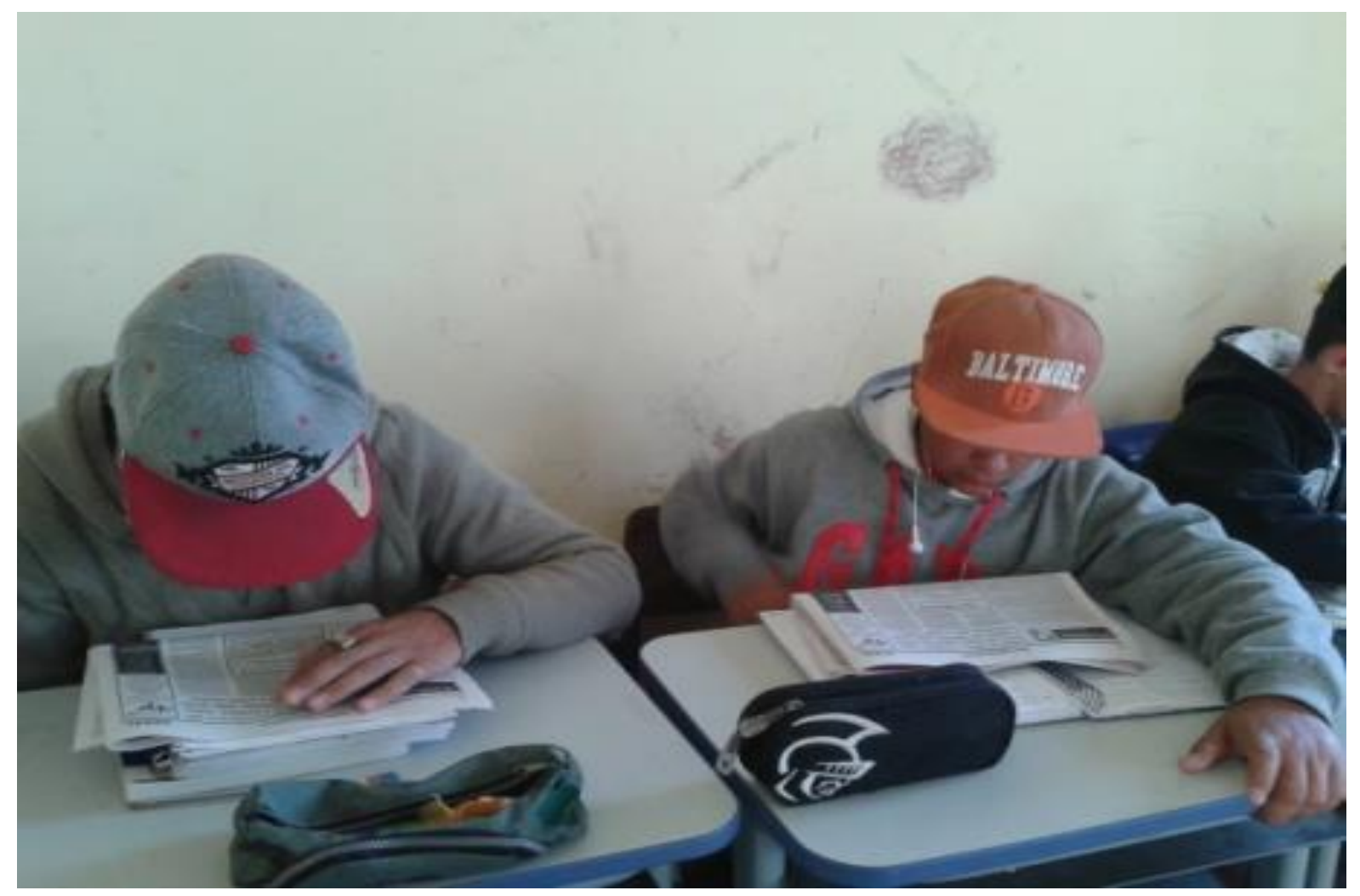


Figura 2: Oficina de textos, análise de notícias, realizada na E. E. E.Dr. Pery da Cunha Gonçalves localizada no município de São Gabriel/RS, na turma de $8^{\circ}$ ano do EF. Fonte: Autores

\section{Oficina 5: Levantamento do conhecimento prévio dos alunos}

Nesta atividade foi solicitado que os alunos conceituassem os termos LIXO, RECICLAGEM e RESÍDUO que apareceram na notícia. Foi feito um levantamento dos conhecimentos prévios que a turma possuía acerca da temática em estudo. As respostas foram escritas no quadro e observadas coletivamente para que se pudesse fazer comparações acerca do que foi exposto. Observou-se que havia poucas diferenças entre as respostas, demonstrando que a turma já possuía um conhecimento de tais conceitos. A seguir, foi feito uma pesquisa em dicionários de três diferentes autores. Houve então um momento de leitura das definições encontradas pelos alunos para comparações entre si e entre as respostas dadas por eles. Concluíram que suas respostas estavam corretas, porém, foram complementadas com as definições encontradas nos dicionários.

Esta atividade proporcionou um momento de aprendizagem significativo para a turma, pois foi realizada coletivamente, através de troca de experiências e conhecimentos, com autonomia dada para que eles mesmos escolhessem a melhor definição, valorizando a sua capacidade, além de conhecer termos técnicos da temática em estudo, ampliando seu vocabulário. A professora ainda observou o uso da linguagem coloquial utilizada pelos alunos em suas definições e pela linguagem padrão dos dicionários, respeitando os espaços de uso de cada uma no cotidiano escolar.

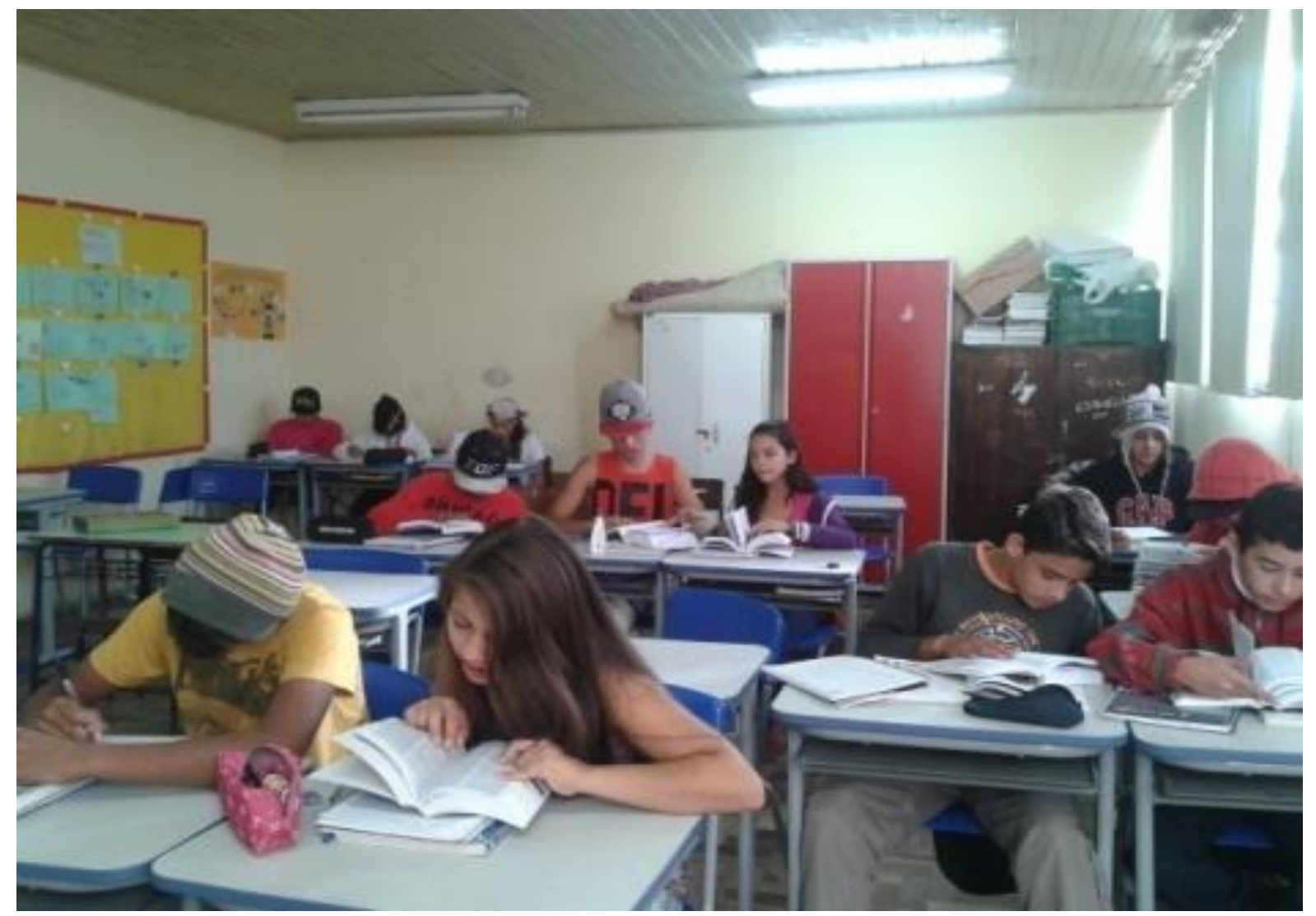

Figura 3: Oficina de Textos, realizada na E. E. E.Dr. Pery da Cunha Gonçalves localizada no município de São Gabriel/RS, na turma de $8^{\circ}$ ano do EF. Fonte: Autores

Oficina 6: Produção de texto do gênero notícia 
Para que esta atividade fosse realizada, a turma planejou um passeio ao redor da escola, no bairro na qual ela se localiza, para verificar as condições ambientais que o mesmo apresentava. Neste momento, os alunos da turma do $8^{\circ}$ ano A se uniram com os alunos do $6^{\circ}$ ano A os quais também estavam desenvolvendo um projeto de EA, para realizar o passeio juntos. Foi uma vivência importante para que os educandos estivessem em contato com a realidade que os rodeia e observassem as atitudes dos moradores em relação ao ambiente no qual vivem. Munidos de máquina fotográfica e de seus próprios celulares fotografaram durante o passeio aquilo que se pode chamar de "flagrantes de descaso com o meio ambiente: muito lixo espalhado nas ruas, bueiros, valetas, pátios e terrenos baldios." Também alguns poucos exemplos de lugares limpos e bem cuidados, moradores que colocam lixo em suas lixeiras, os quais foram destacados pelos próprios alunos.

Após esta atividade, foi solicitado aos alunos que utilizassem suas fotografias e criassem uma notícia sobre o fato que mais lhe chamasse a atenção em relação ao cuidado com o meio ambiente no bairro onde moravam. Os alunos que moravam em outros bairros optaram por fazer o trabalho de acordo com a sua realidade, fazendo a visitação e fotografando em outro horário, e assim formaram-se novos grupos que saíram a campo, observando as condições ambientais dos bairros que rodeiam a escola. Este fato destaca-se pela iniciativa dos alunos, por tomada de decisões e pela autonomia na hora da observação e pesquisa. São atitudes como esta que formam cidadãos críticos e atuantes e não apenas meros repetidores de conceitos. Os textos produzidos foram entregues como trabalho final do projeto e foram expostos em mural na escola.

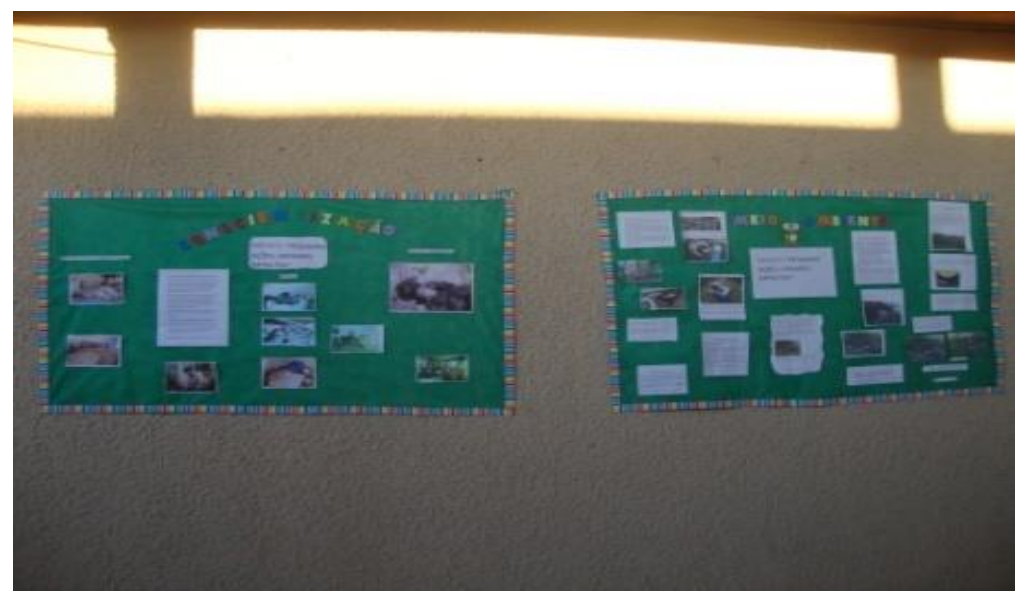

Figura 4: Painel de exposição dos textos na E. E. E.Dr. Pery da Cunha Gonçalves localizada no município de São Gabriel/RS, da turma de $8^{\circ}$ ano do EF. Fonte: Autores

Para a complementação de saberes, convidou-se a presidente da associação de catadores do Projeto Minuano para visitar a escola e palestrar sobre o seu trabalho. Na oportunidade, a presidente, senhora Maria Otília, explicou o que é a coleta seletiva, lixo orgânico e lixo seco, além prestar esclarecimentos sobre os dias nos quais é feita a coleta nos bairros aos arredores da escola, o trabalho dos catadores com o lixo arrecadado e seu destino.

A turma foi convidada a conhecer o galpão onde o trabalho de separação e seleção do lixo é feito em São Gabriel. No dia combinado, a turma visitou as dependências onde é feito este trabalho e conheceu cada etapa, desde a separação, a prensa, o acondicionamento para venda e a importância desta atividade para o meio ambiente e para o sustento das famílias que dela sobrevivem. 


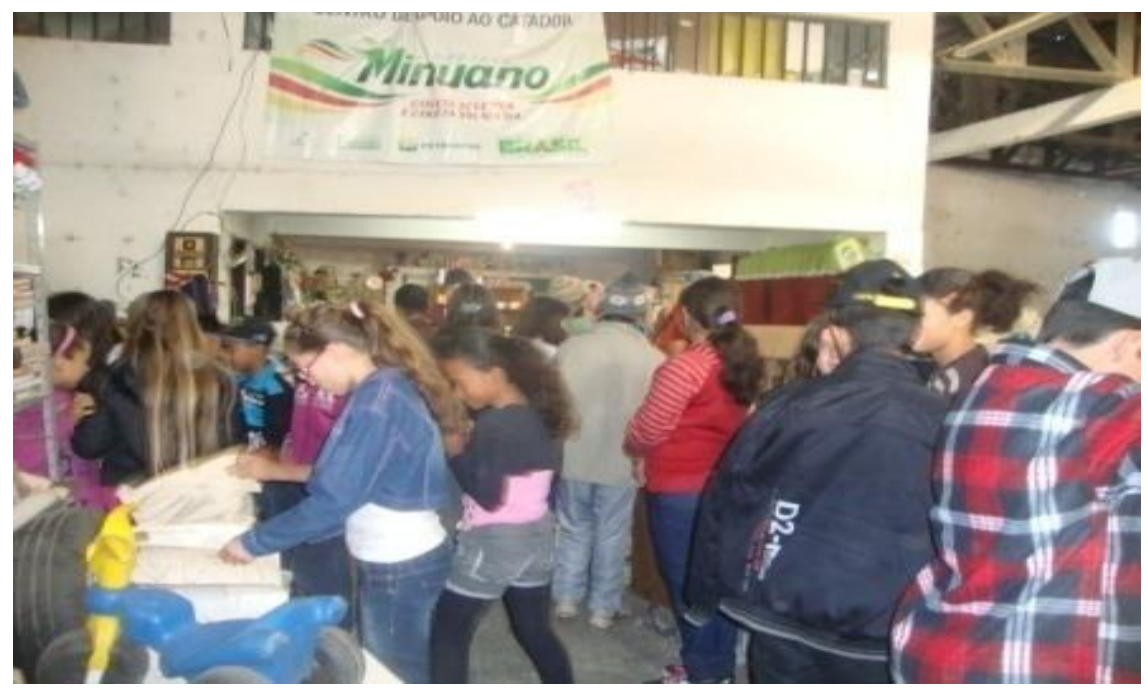

Figura 5: Visita ao galpão de coleta seletiva, realizada pela turma do 8ªno A do EF da E. E. E. Dr. Pery da Cunha Gonçalves localizada no município de São Gabriel/RS. Fonte: Autores

Finalizando as atividades do projeto, foi decidido pela turma realizar uma campanha de conscientização na escola e no bairro aos arredores da mesma. Salienta-se que esta ideia partiu de uma aluna e foi desenvolvida por todos com o apoio da turma do $6^{\circ}$ ano, que como já foi citado, também desenvolvia um projeto de EA. Aliados no mesmo ideal, os alunos organizaram-se em grupos e visitaram todas as turmas do EF, nos turnos manhã e tarde, distribuindo panfletos explicativos sobre coleta seletiva e expondo seu trabalho, pedindo a colaboração de todos para a separação dos lixos residenciais, além de cuidar da limpeza na própria escola. Para melhor identificar-se, vestiram um colete verde feito de TNT que os próprios alunos confeccionaram.

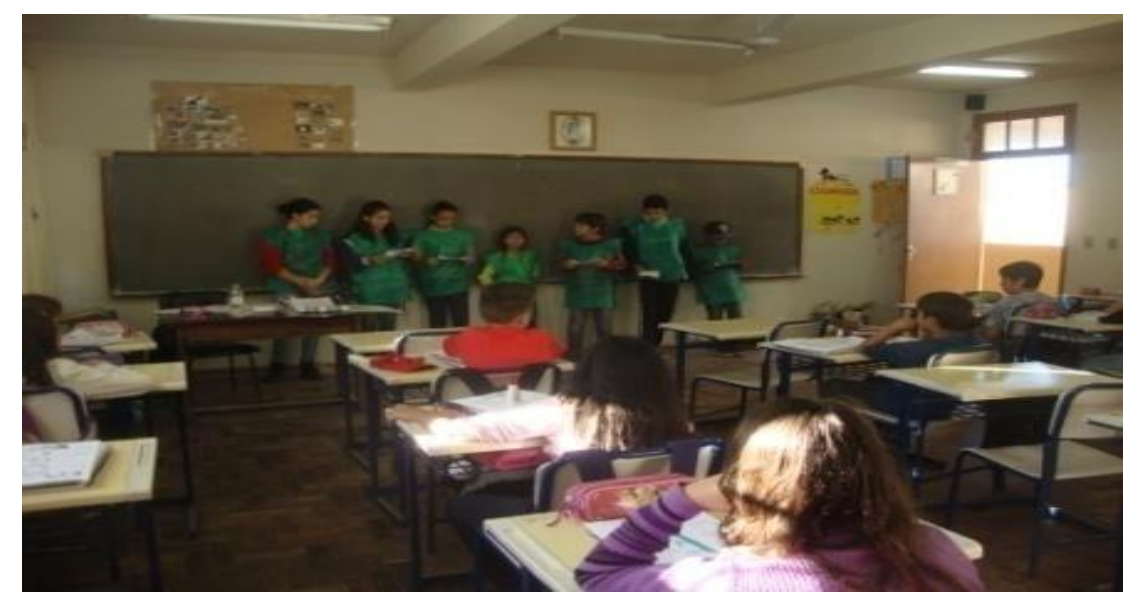

Figura 6: Campanha de conscientização realizada pela turma do 8ºano A do EF da E. E. E.Dr. Pery da Cunha Gonçalves localizada no município de São Gabriel/RS. Fonte: Autores

Outra atividade realizada pelos grupos foi a de monitoramento do recreio na qual durante alguns dias por semana, os alunos caracterizados acompanhavam o recreio e conversavam com os colegas sobre a higiene na escola e sobre a coleta seletiva. A última atividade realizada foi a campanha no bairro, onde os alunos visitaram os moradores, entregaram folhetos explicativos nas casas das ruas próximas à escola. 


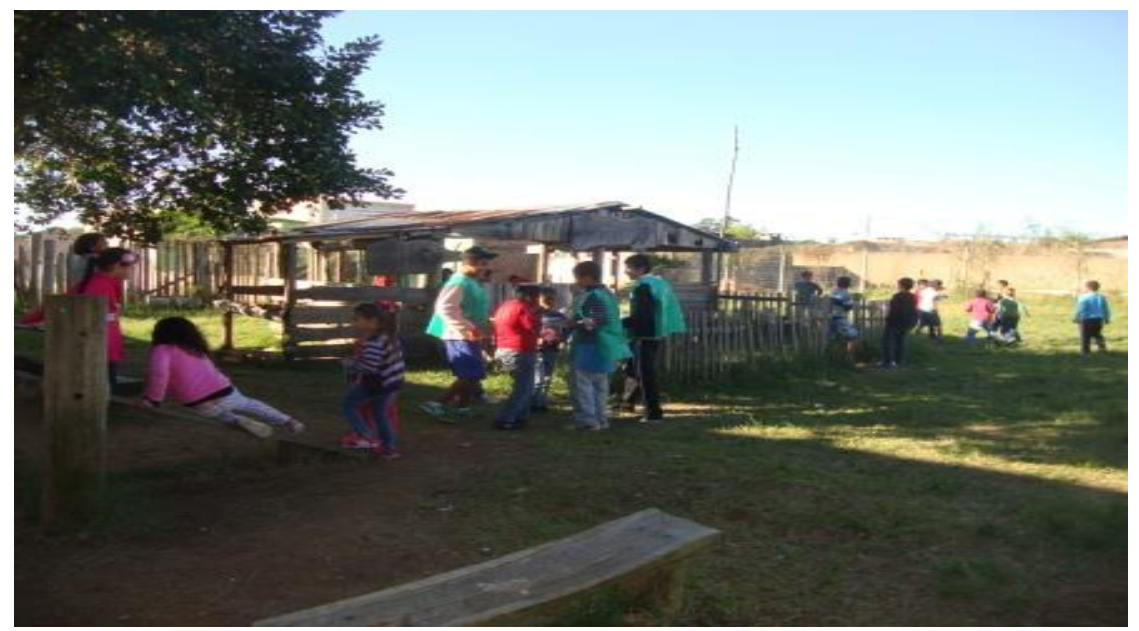

Figura7: Campanha de conscientização realizada pela turma do 8ano A do EF da E. E. E.Dr. Pery da Cunha Gonçalves localizada no município de São Gabriel/RS. Fonte: Autores

\section{Refletindo sobre o caminho percorrido}

Diante do que foi exposto, percebe- se que o trabalho com as oficinas de textos propicia o desenvolvimento no educando de seu potencial reflexivo e crítico que se manifestou não só através dos debates realizados, dos textos produzidos, mas principalmente, das ações realizadas em prol da conscientização da comunidade escolar em relação aos cuidados com o meio ambiente. Ações estas que foram planejadas e realizadas em conjunto, demonstrando o comprometimento de todos os alunos que participavam dos trabalhos.

As oficinas serviram também como forma de proporcionar aos educandos uma aprendizagem significativa de conhecimentos através da leitura, interpretação e escrita de textos, abrindo um espaço para a mediação do professor, de modo a ressignificar a sua prática pedagógica. Esta abertura para o novo levou-o ao autoconhecimento, ou seja, desenvolveu suas habilidades comunicativas e perceptivas de seus alunos, aproximando-os de forma a criar laços que os uniram, numa atitude recíproca de crescimento pessoal.

O planejamento das atividades foi direcionado para o trabalho em pequenos grupos para que houvesse troca de experiências que favorecesse o aprendizado, visto que os alunos apresentavam muita resistência às atividades de leitura e escrita. Além disso, o ambiente da sala de aula tornou-se agradável e favoreceu a organização das tarefas de forma a responsabilização de todos pelos resultados obtidos. Na medida em que as atividades foram requerendo maior concentração e esforço, a turma correspondeu de forma positiva, auxiliando os colegas com maior dificuldade.

A prática-pedagógica baseada na autonomia dos alunos na realização das atividades, com vistas à compreensão de sua realidade, torna o processo de ensino-aprendizagem muito mais dinâmico. Por isso, foi possível desenvolver as oficinas concomitantemente com os conteúdos gramaticais previstos no plano de trabalho da professora para esta turma.

Sendo assim, a turma realizou no trimestre três avaliações com peso dez (10), somando ao todo trinta (30) pontos. A primeira e a terceira avaliação foram provas objetivas de conteúdos gramaticais dados, leitura e interpretação de textos dos gêneros trabalhados em aula. A segunda avaliação consistiu na soma dos trabalhos realizados em aula, incluindo as produções escritas dos alunos. 
A seguir, apresenta-se um gráfico do resultado das avaliações feitas na turma do $8^{\circ}$ ano A, pela professora regente da disciplina de Língua Portuguesa no primeiro trimestre de dois mil e quinze:

Gráfico 1: Avaliações de Português

\section{Avaliações de Português 10 Trimestre de 2015}

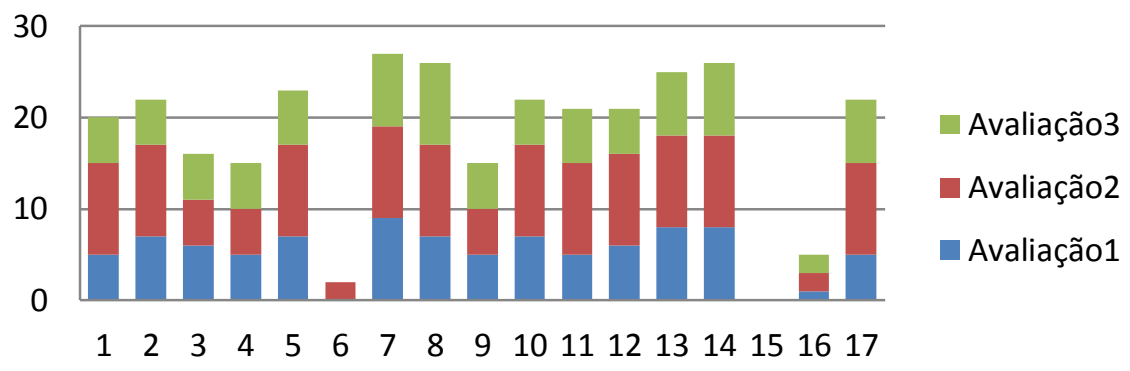

Fonte: Autores

Observa-se pelo gráfico o resultado positivo da turma neste trimestre, com apenas três alunos sem média num total de dezessete alunos. Sendo que o aluno de número quinze (15) não está freqüentando e a direção da escola já tomou as devidas providências.

Analisando o resultado obtido pela turma diante da mudança metodológica realizada pela professora neste trimestre, pode-se observar o gráfico comparativo dos últimos cinco (5) anos de turmas do mesmo nível, nesta disciplina, tendo em vista que a professora regente era a mesma em questão.

Gráfico 2: Alunos com média e sem média

\section{Avaliação de Português 10 Trimestre}

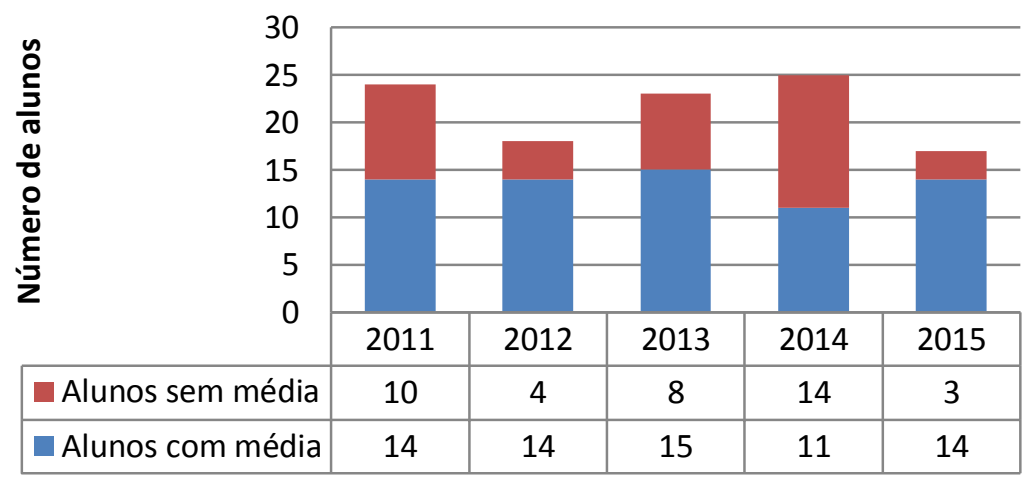

Fonte: Autores

A análise do gráfico acima confirma o melhor resultado no ano de dois mil e quinze, principalmente em relação ao ano anterior. Observando-se o ano de dois mil e doze, percebe-se um resultado positivo aproximado, porém os resultados obtidos naquele ano são inferiores, pois dos quatorze alunos que atingiram a média, treze obtiveram média menor que vinte (20),considerado resultado regular. Já no presente ano, dos quatorze alunos que atingiram a média, onze obtiveram médio acima de vinte pontos, considerado um resultado muito bom. 
Os resultados são consequência de um trabalho planejado e construído com responsabilidade. Os demonstrativos revelam novos caminhos a serem percorridos e não um fim em si mesmo. A avaliação é um processo constante de busca e construção de práticas pedagógicas que garantam a real aprendizagem, é um guia de como o professor deve caminhar com a sua turma e realizar seu trabalho.

\section{$4 \quad$ Considerações Finais}

Ao encerrar o trabalho no trimestre, observou-se uma turma com um perfil bem diferente daquele antes do início do mesmo. Não é só em relação à aprendizagem, no sentido de maior responsabilidade, comprometimento e atenção, mas principalmente, nas relações interpessoais da turma entre si, e da turma com a professora. Levando-se em conta todos estes aspectos, é grande a responsabilidade da professora em dar continuidade ao trabalho interdisciplinar, já que é uma exigência da turma que quer dar prosseguimento, propondo novas atividades que serão avaliadas e planejadas para o segundo semestre.

Com relação à Educação Ambiental, é óbvio que uma atividade não vai dar conta de tantas questões pertinentes a este tema transversal, já que muitas vezes nos deparamos com aspectos culturais que entram em choque com a necessidade de mudança de hábitos e atitudes da família e da comunidade. Porém, os adolescentes pela sua capacidade crítica têm mais facilidade de compreender e aceitar as mudanças, se lhes for dada a oportunidade de fazer reflexões e de conhecer as necessidades do meio em que vivem, além de seu poder transformador no seio da família e da comunidade escolar.

A Educação Ambiental é um tema que deve fazer parte do dia a dia no ambiente escolar, dada a abrangência e a importância desse assunto para todos. Por isso, aliar o estudo deste tema transversal com o estudo do gênero jornalístico foi uma boa estratégia para desenvolver habilidades de leitura, compreensão de textos e a produção escrita. Os alunos tiveram várias oportunidades para desenvolver suas capacidades, organizadas em oficinas de leitura, interpretação e produções textuais, além de realizarem o trabalho em pequenos grupos de forma cooperativa, facilitando a aprendizagem pela troca de experiências e pela ação mediadora da professora. As atividades de leitura e produção escrita que antes eram consideradas pelos educandos maçantes e não lhes chamavam a atenção, de repente, tornaram-se prazerosas e muito eficientes.

A adequação do tempo foi necessária para o desenvolvimento das atividades, pois no início, foi planejado ocupar duas das cinco horas-aula por semana da disciplina de Língua Portuguesa, mas depois houve a necessidade de usar horas a mais, principalmente nas atividades extraclasse, como a palestra e os passeios, o que contamos com o apoio e a compreensão dos demais colegas e a supervisão.

A perspectiva de trabalho interdisciplinar, através da transversalidade, proporciona uma educação com a visão integral do sujeito, evitando o ensino fracionado, dissociado da realidade do educando e que na maioria das vezes, não atrai a sua atenção porque não tem sentido algum, tornandoo apático e ausente. Ele não se sente parte integrante da ação em sala de aula, pois é tratado como objeto, já que recebe tudo pronto. A interdisciplinaridade permite que o aluno faça parte, no sentido de agir, de participar e de construir caminhos que o levem à aprendizagem.

O papel do educador neste processo é tornar o ensino mais dinâmico, promovendo a socialização e a colaboração, de forma que mesmo aqueles que possuem maior dificuldade, possam participar e se sentir capaz de aprender. Nesse contexto, a interdisciplinaridade surge como uma prática 
que atende às necessidades do aluno e do professor que busca novos caminhos numa profissão de múltiplas responsabilidades e desafios.

\section{Referências Bibliográficas}

ACSELRAD, Henri; VIEIRA, Liszt \& GUARANY, Reinaldo. Ecologia Direito do Cidadão. Rio de Janeiro: Gráfica JB, 1993.

BRASIL. Parâmetros Curriculares Nacionais: Meio Ambiente e Saúde/ Temas Transversais. Secretaria de Educação Fundamental. Brasília: MEC/SEF,V.9,1997.

BRASIL. Parâmetros Curriculares Nacionais: Língua Portuguesa / Secretaria de Educação Fundamental. Brasília: MEC/SEF, V.2,1997.

FAZENDA, Ivani. Interdisciplinaridade: História, Teoria e Pesquisa. 18. ed., São Paulo: Papirus Editora, 2014

FAZENDA, Ivani. Didática e Interdisciplinaridade. 17 ed. São Paulo: Papirus Editora, 2013.

FILHO, Francisco Alves. Gêneros Jornalísticos/notícias e cartas de leitor no ensino fundamental. São Paulo: Cortez Editora, 2011.

HUTCHISON, David. Educação Ecológica: ideias sobre consciência ambiental. Porto Alegre: Artes Médicas Sul, 2000. MÜLLER, Jackson. Educação Ambiental: Diretrizes para a prática pedagógica. Porto Alegre/RS: Edição FAMURS.

SCHNEUWLY, Bernard; DOLZ, Joaquim. Gêneros orais e escritos na escola. São Paulo: Mercado de Letras Edições e Livraria LTDA, 2013. 